\title{
Ultrasonic Mitigation Investigation
}
B. P. Hildebrand
C. L. Shepard

April 1993

Prepared for the U.S. Department of Energy under Contract DE-AC06-76RLO 1830

Pacific Northwest Laboratory

Operated for the U.S. Department of Energy by Battelle Memorial Institute

DISTRIBUTION OF THIS DOCUMENT IS UNLIMITED

$$
\begin{gathered}
\text { PEr m } \\
\text { MAY } 111993 \\
0571
\end{gathered}
$$




\title{
DISCLAIMER
}

This report was prepared as an account of work sponsored by an agency of the United States Government. Neither the United States Government nor any agency thereof, nor Battelle Memorial Institute, nor any of their employees, makes any warranty, expressed or implied, or assumes any legal liability or responsibility for the accuracy, completeness, or usefulness of any information, apparatus, product, or process disclosed, or represents that its use would not infringe privately owned rights. Reference herein to any specific commercial product, process, or service by trade name, trademark, manufacturer, or otherwise does not necessarily constitute or imply its endorsement, recommendation, or favoring by the United States Government or any agency thereof, or Battelle Memorial Institute. The views and opinions of authors expressed herein do not necessarily state or reflect those of the United States Government or any agency thereof.

\author{
PACIFIC NORTHWEST LABORATORY \\ operated by \\ BATTELLE MEMORIAL INSTITUTE \\ for the \\ UNITED STATES DEPARTMENT OF ENERGY \\ under Contract DE-AC06-76RLO 1830
}

Printed in the United States of America

Available to DOE and DOE contractors from the

Office of Scientific arid Technical Information, P.O. Box 62, Oak Ridge, TN 37831; prices available from (615) 576-8401. FTS 626-8401.

Available to the public from the National Technical Information Service, U.S. vepartment of Commerce, 5285 Port Royal Rd., Springfield, VA 22161. 
B. P. Hildebrand

C. L. Shepard

April 1993

Prepared for the U.S. Department of Energy under Contract DE-AC06-76RLO 1830

Pacific Northwest Laboratory

Richland, Washington 99352

DISTRIBUTION OF THIS DOCUMENT IS UNLIMITED

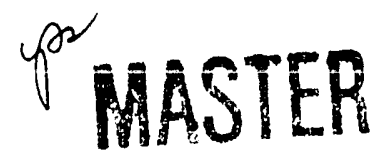




\section{SUMMARY}

The suggestion was made that the introduction of ultrasound into Tank 101-5Y might serve to release the hydrogen bubbles trapped in the slurry. This would cause a continuous release of bubbles and thereby prevent the turnover phenomenon. Two major considerations were 1) the method for delivering the energy into the slurry and 2) the effective volume of action. In this study, we attacked the former by designing and testing a liquid-filled waveguide and radiator, and the latter by making ultrasonic property measurements on synthetic waste. Our conclusion is that ultrasonic mitigation may not be feasible, primarily because of the very high attenuation (1000 to $5000 \mathrm{~dB} / \mathrm{m}$ ) factor at 10 to $30 \mathrm{kHz}$. Such a high attenuation would restrict the action volume to such a low value as to make the method impractical. Further investigations are recommended to identify the cause of this effect and determine if this same effect will be seen in real 101-SY waste. 


\section{CONTENTS}

SUMMARY . . . . . . . . . . . . . . . . . . . . . . i

INTRODUCTION . . . . . . . . . . . . . . . . . . . . 1

DESCRIPTION . . . . . . . . . . . . . . . . . . . . . 3

ACOUSTIC DELIVERY SYSTEM . . . . . . . . . . . . . . . . 3

ULTRASONIC PROPERTY MEASUREMENT . . . . . . . . . . . . . . . . 13

ATTENUATION MEASUREMENTS . . . . . . . . . . . . . . 13

DEGASSING EXPERIMENTS . . . . . . . . . . . . . . . . 16

EXPERIMENTS IN HEATED SLURRY . . . . . . . . . . . . . . . 23

EXPERIMENTS IN PRESSURIZED SLURRY . . . . . . . . . . . . . 25

EXPERIMENTS IN DILUTED SLURRY . . . . . . . . . . . . . 27

MITIGATION POWER EXPERIMENT . . . . . . . . . . . . . . 27

CONCLUSIONS . . . . . . . . . . . . . . . . . . . . . . . . 29

REFERENCES . . . . . . . . . . . . . . . . . . . . 31

BIBLIOGRAPHY . . . . . . . . . . . . . . . . . . . . 33

APPENDIX A: FORMULATION AND CONDITIONING OF THE WASTE SIMULANT . . . . A.1 


\section{FIGURES}

1. Prototype Liquid-Filled Waveguide System . . . . . . . . 7

2. Graph of Radiator Output Pattern at Two Distances . . . . . . . 11

3. Experimental System for Ultrasonic Property Measurenient . . . . . . . 14

4. Attenuation Measurements for a Chemical Simulant Slurry at Room Temperature and Ambient Pressure ............ 16

5. Simulant Slurry and Bubbles at Atmospheric Pressure and Under Vacuum 19

6. Acoustic Attenuation in a De-Gassed Slurry . . . . . . . . . . 21

7. Acoustic Resonance Frequency for Air Bubbles in Water . . . . . . . 22

8. Graph of the Effect of Pressure on Coupling . . . . . . . . . 26

\section{$\underline{\text { TABLES }}$}

1. Cutoff Frequency in Hertz as a Function of Pipe Diameter and Liquid

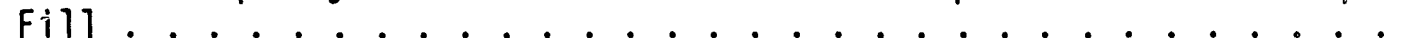

2. Attenuation and Cavitation Threshold at $20 \mathrm{kHz}$ in a Fluid-Filled 38-mm Diameter Circular Waveguide ........... 6

3. Membrane Thickness for a 10 -Membrane Radiator for $20 \mathrm{kHz}$. . . . 9 9

4. Acoustic Attenuation of Chemical Simulant at Various Frequencies and Void Fractions .................... 17

5. Attenuation as a Function of Pressure ............ 25

6. Velocity and Cavitation Threshold as a Function of Temperature and Pressure .................. 27

7. Attenuation as a Function of Dilution and Pressure . . . . . . 27

A.1. Composition of Synthetic Waste used for Chemical Simulant Testing -

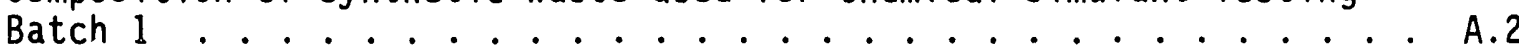

A.2. Composition of Synthetic Waste used for Chemical Simulant Testing Batch 2................... A.3 


\section{INTRODUCTION}

There is a large body of literature describing the application of highpower ultrasonics to a variety of industrial problems. Of particular interest is the literature on welding, ultrasonic cleaning, foam control, emulsification, and liquid atomization. These and other applications are described in some detail by Ensminger (1973). Another body of literature describes the propagation of sound in ducts anci is well described in Pierce (1981). Together these books provide the theory necessary for the investigation of this problem.

As mentioned in the summary. we divided the problem into two segments: 1) the ultrasonic delivery system and 2) ultrasonic property measurement of the waste. Ordinarily, we would have performed the second task first, because a negative result would obviate the need for doing the first task. However, we had a very short time schedule, so decided to do both concurrently. 


\section{DESCRIPTION}

The following paragraphs describe the work that was performed and the results obtained. A library search to incate relevant texts and articles revealed extensive theory and experience in related fields. It also provided information on commercially available equipment of sufficient acoustic power for our purposes. This, in turn, guided the selection of frequency, since this equipment was designed for specific lower frequencies. It turned out that our experiments with simulants further strengthened the requirement for low frequencies to limit attenuation. Two books (Ensminger 1973 and Pierce 1981) provided the necessary information to carry out our research, al though numerous additional books provided detail and clarification. These will be listed in the bibliography.

\section{ACOUSTIC DELIVERY SYSTEM}

The acoustic delivery system will consist of high-power electronics, a converter or transducer, a horn to match the transducer diameter to the waveguide diameter, a waveguide, and a radiator. The commercial electronics and converter assembly can typically provide about $3 \mathrm{k} / \mathrm{N}$ of acoustical power at $20 \mathrm{kHz}$. Custom-designed equipment for higher powers can be obtained at lower frequencies. Generally the higher the frequency, the less delivered power.

The waveguide we decided on was based on the commercially available 20$\mathrm{KHz}$ system. This frequency dictates the diameter of the waveguide, whether solid or liquid-filled. Since Los Alamos National Laboratory (LANL) was investigating the solid waveguide, we concentrated on the liquid-filled version. According to Pierce, in order to transmit a plane wave down a circular waveguide, the frequency must obey the inequality

$$
\omega<1.841 \frac{c}{a}
$$

where $c=$ velocity of propagation in the chosen liquid and $a=$ radius of the waveguide. 
Frequencies higher than this will be evanescent and hence die out in a short distance. For a $20-\mathrm{kHz}$ signal, therefore, the diameter should be $4.34 \mathrm{~cm}$ ( 1.71 in.) for a water-filled cylinder. Table 1 shows the cutoff frequency for a variety of standard pipe sizes filled with four types of liquid, plus a solid steel guide. Note that a $3.81 \mathrm{~cm}$ (1.5 in.) diameter pipe is suitable for a $20-\mathrm{kHz}$ wave for all but the high viscosity silicone $0 i 1$.

The first problem to arise is the cavitation threshold of the liquid contents of the waveguide. In general, liquids have relatively low cavitation thresholds, on the order of $1-5$ watts $/ \mathrm{cm}^{2}$. These values are modified by temperature, pressure, and pulse length.

A second problem, although not usually significant, is attenuation of the wave as it propagates down the waveguide. This attenuation is due primarily

TABLE 1. Cutoff Frequency in Hertz as a Function of Pipe Diameter and Liquid Fill

\begin{tabular}{||c|c|c|c|c|c||}
\hline $\begin{array}{c}\text { Fipe } \\
\text { Size, } \\
\text { in. }\end{array}$ & $\begin{array}{c}\text { Cutoff } \\
\text { Water }\end{array}$ & $\begin{array}{c}\text { Cutoff } \\
\text { Transformer } \\
\text { 0i1 }\end{array}$ & $\begin{array}{c}\text { Cutoff } \\
\text { Silicone } \\
\text { 0il }\end{array}$ & $\begin{array}{c}\text { Cutoff } \\
\text { Silicone } \\
\text { (30 poise) }\end{array}$ & Stee \\
\hline 0.125 & 273,783 & 256,437 & 248,468 & 182,835 & $1,078,256$ \\
\hline 0.25 & 136,892 & 128,219 & 124,234 & 91,417 & 539,128 \\
\hline 0.375 & 91,261 & 85,479 & 82,823 & 60,945 & 359,419 \\
\hline 0.5 & 68,446 & 64,109 & 62,117 & 45,709 & 269,564 \\
\hline 0.75 & 45,631 & 42,740 & 41,411 & 30,472 & 179,709 \\
\hline 1 & 34,223 & 32,055 & 31,058 & 22,854 & 134,782 \\
\hline 1.25 & 27,378 & 25,644 & 24,847 & 18,283 & 107,826 \\
\hline 1.5 & 22,815 & 21,370 & 20,706 & 15,236 & 89,855 \\
\hline 2 & 17,111 & 16,027 & 15,529 & 11,427 & 67,391 \\
\hline 2.5 & 13,689 & 12,822 & 12,423 & 9,142 & 53,913 \\
\hline 3 & 11,408 & 10,685 & 10,353 & 7,618 & 44,927 \\
\hline 3.5 & 9,778 & 9,158 & 8,874 & 6,530 & 38,509 \\
\hline 4 & 8,556 & 8,014 & 7,765 & 5,714 & 33,695 \\
\hline
\end{tabular}


to the boundary layer, and not the fluid itself. The expression for the attenuation is

$$
\alpha_{w}=\left(\frac{\omega \mu}{8 \rho c^{2}}\right)^{1 / 2} \frac{L_{p}}{A}\left(1+\frac{\gamma-1}{P_{r}^{1 / 2}}\right)
$$

where $\mu=$ viscosity

$\rho=$ density

$L_{p}=$ circumference of the waveguide

$A=$ cross-sectional area of the waveguide

$\gamma=$ ratio of specific heats

$P_{r}=P_{\text {rand }} l^{\prime}$ 's number.

Table 2 presents values of cavitation threshold and attenuation in a $3.81-\mathrm{cm}$ waveguide filled with a variety of fluids. Note that the attenuation is acceptable, but cavitation thresholds are low. As mentioned earlier, thresholds can be increased by pressure and by pulsing the sound. For example, an external pressure of 1 atm approximately doubles the cavitation threshold. Pulsing the sound with pulse lengths of 5 to $10 \mathrm{msecs}$ doubles the threshold once again. Therefore, the cavitation threshold for GE SF1154 silicone oil can conceivably by raised to 15 to $20 \mathrm{~W} / \mathrm{cm}^{2}$ without undue effort. A third variable, frequency, is not available to us since we are restricted to low frequencies.

Given these results, it becomes obvious that none of the liquids listed can support the transport of $3 \mathrm{~kW}$ of energy in view of the small cross-section of the waveguide. We might, however, consider mercury as the liquid. It has about the same propagation velocity as water, and one fourth the attenuation. It has no dissolved gases, so will not cavitate unless impurities are present. The major problems with mercury are weight, toxicity, and difficulty in wetting.

The last component of the acoustic delivery system is the radiator. This component, attached to the bottom end of the waveguide, serves to convert the downward traveling plane wave to a horizontally traveling cylindrical wave. 
TABLE 2. Attenuation and Cavitation Threshold at $20 \mathrm{kHz}$ in a Fluid-Filled 38-mm Diameter Circular Waveguide

\begin{tabular}{||l|c|c|c|c|c|c||}
\hline \multicolumn{1}{|c|}{ Fluid } & $\begin{array}{c}\text { Viscosity, } \\
\text { poise }\end{array}$ & $\begin{array}{c}\text { Velocity, } \\
\mathrm{m} / \mathrm{sec}\end{array}$ & $\begin{array}{c}\text { Density, } \\
\mathrm{kg} / \mathrm{m}^{3}\end{array}$ & $\begin{array}{c}\text { Threshold, } \\
\text { watt/cm }\end{array}$ & Attenuation & $\begin{array}{c}\text { Attenuation, } \\
\mathrm{dB} / \mathrm{m}\end{array}$ \\
\hline $\begin{array}{l}\text { Xylene hexa- } \\
\text { flouride }\end{array}$ & 0.0084 & 879 & 1370 & 0.9 & $1.175 \mathrm{E}-02$ & $5.134 \mathrm{E}-02$ \\
\hline $\begin{array}{l}\text { Carbon tetra- } \\
\text { chloride }\end{array}$ & 0.0098 & 926 & 1595 & 1 & $1.111 \mathrm{E}-02$ & $4.853 \mathrm{E}-02$ \\
\hline Water & 0.01 & 1480 & 1000 & 1 & $8.870 \mathrm{E}=03$ & $3.869 \mathrm{E}-02$ \\
\hline Kerosene & 0.04 & 1324 & 810 & 1.9 & $2.203 \mathrm{E}-02$ & $9.676 \mathrm{E}-02$ \\
\hline G.E. Transil & 0.131 & 1350 & 880 & 2.3 & $3.752 \mathrm{E}-02$ & $1.661 \mathrm{E}-01$ \\
\hline $\begin{array}{l}\text { Dimethyl } \\
\text { phthalate }\end{array}$ & 0.178 & 1463 & 1176 & 3 & $3.491 \mathrm{E}-02$ & $1.543 \mathrm{E}-01$ \\
\hline Sperm oil & 0.25 & 1440 & 880 & 3.3 & $4.859 \mathrm{E}-02$ & $2.163 \mathrm{E}-01$ \\
\hline Linseed oil & 0.38 & 1468 & 921 & 2.1 & $5.744 \mathrm{E}-02$ & $2.509 \mathrm{E}-01$ \\
\hline Corn oil & 0.63 & 1463 & 914 & 3.5 & $7.450 \mathrm{E}-02$ & $3.362 \mathrm{E}-01$ \\
\hline Olive oil & 0.84 & 1431 & 912 & 5 & $8.804 \mathrm{E}-02$ & $4.003 \mathrm{E}-01$ \\
\hline $\begin{array}{l}\text { G.E. SF1154 } \\
\text { silicone }\end{array}$ & 1.9 & 1255 & 994 & & $1.446 \mathrm{E}-01$ & $6.784 \mathrm{E}-01$ \\
\hline Castor oil & 6.3 & 1477 & 969 & 5.3 & $2.266 \mathrm{E}-01$ & $1.116 \mathrm{E}+00$ \\
\hline
\end{tabular}

In this way, a maximum voiume of waste would be subjected to ultrasonic mitigation.

The radiator we designed consists of a section of waveguide into which are inserted a set of $45^{\circ}$ conical reflectors as shown in Figure 1 . The reflectors vary in thickness according to the equation

$$
t=\left(\frac{R}{1-R}\right)^{1 / 2} \frac{2 Z}{\rho \omega \cos \theta}
$$

where $Z$ = acoustic impedance of the fluid

$\rho=$ density of the reflector

$R=$ desired fraction of amplitude reflected

$\theta=$ angle of incidence 


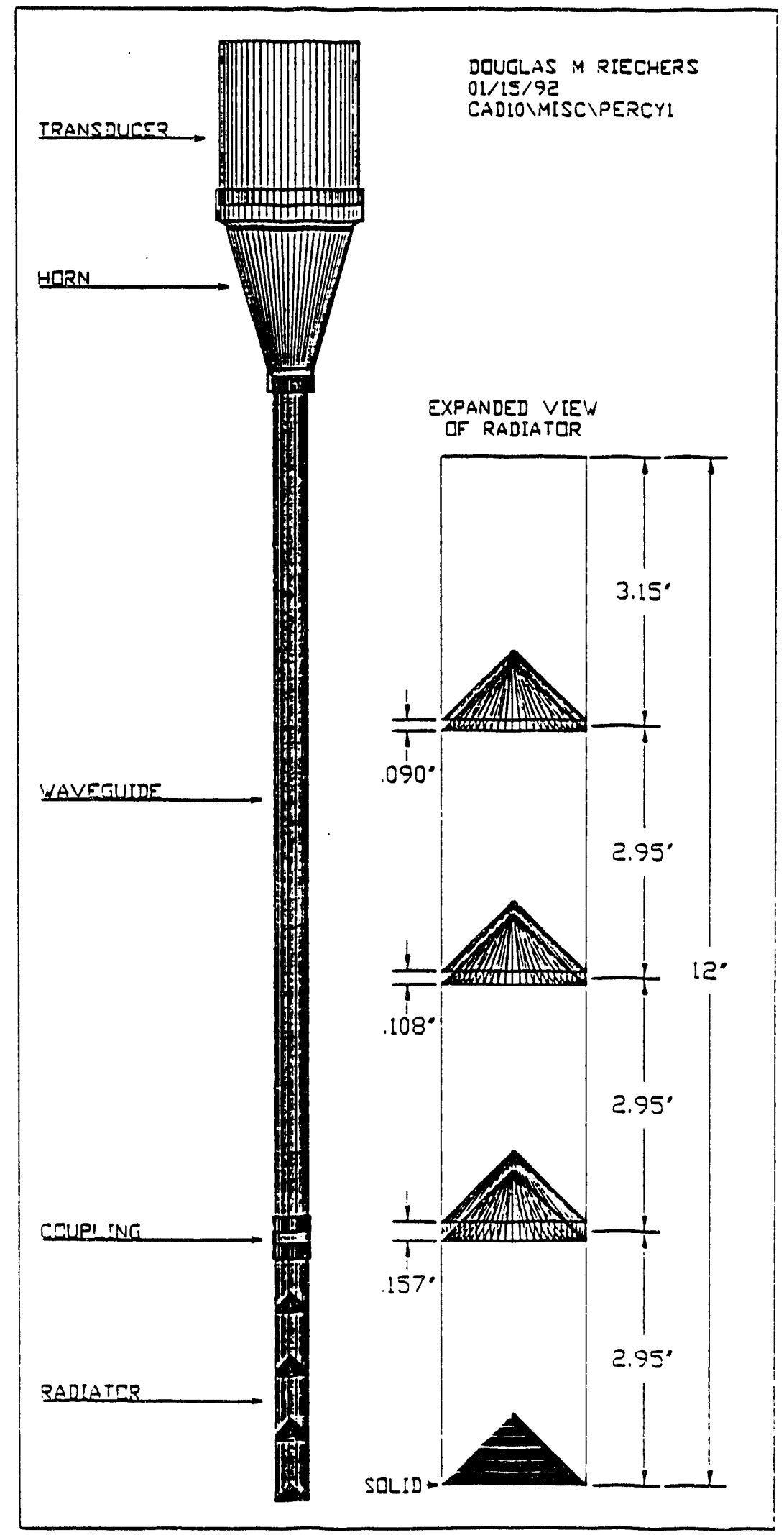

FIGURE 1. Prototype Liquid-Filled Waveguide System 
These reflectors are placed at intervals of one wavelength and are designed to reflect equal amplitudes. Thus, each succeeding reflector must reflect a greater proportion of its incident energy, resulting in increasing thickness with depth. Thus,

$$
R_{n}=\frac{1}{N+1-n}
$$

where $N=$ total number of reflectors.

Substituting Eq. (4) into Eq. (3) yields an expression for reflector thickness as a function of position.

$$
t_{n}=\left(\frac{1}{N-n}\right)^{1 / 2} \frac{2 Z}{\rho \omega \cos \theta}
$$

Table 3 gives the example of a 10 -reflector radiator that will reflect equal energy from each reflector. Because the reflectors are spaced at wavelength intervals, the sum of the reflections add up to a smooth cylindrical wave.

The reflected wave must pass through the radiator wall into the waste with maximum efficiency. Eq. (3) can be used to determine the thickness of the radiator wall by setting the reflection coefficient to a low value, say $1 / 10$. In this case, the thickness should be approximately $0.1 \mathrm{~cm}$, which will provide $90 \%$ transmission of the sound amplitude into the waste.

The final design of the prototype acoustic power delivery system would therefore consist of a $20-\mathrm{kHz}, 3 \mathrm{~kW}$ commercial unit driving a transducer. The transducer would be coupled to the waveguide by a solid steel horn with the output aperture inserted into it. The waveguide would consist of $1-1 / 2$ in. Schedule 40 stainless steel tubing filled with a fluid, preferably mercury. This tube would be long enough to reach from above ground to the slurry layer to be mitigated (approximately $40 \mathrm{ft}$ ). The radiator would consist of $1-1 / 2$ in. Schedule 5 stainless steel tubing with conical reflectors every wavelength over a length of approximately $1 \mathrm{~m}$. Such a radiator would have a surface area of approximately $1200 \mathrm{~cm}^{2}$. If $1 \mathrm{watt} / \mathrm{cm}^{2}$ is the desired output intensity, the 
TABLE 3. Membrane Thickness for a 10-Membrane Radiator for $20 \mathrm{kHz}$

\begin{tabular}{|c|c|c|}
\hline Membrane Number & Reflectivity & Thickness, cm \\
\hline 1 & $i / 10$ & 0.144 \\
\hline 2 & $1 / 9$ & 0.153 \\
\hline 3 & $1 / 8$ & 0.164 \\
\hline 4 & $1 / 7$ & 0.177 \\
\hline 5 & $1 / 6$ & 0.194 \\
\hline 6 & $1 / 5$ & 0.216 \\
\hline 7 & $1 / 4$ & 0.250 \\
\hline 8 & $1 / 3$ & 0.306 \\
\hline 9 & $1 / 2$ & 0.433 \\
\hline 10 & 1 & large \\
\hline
\end{tabular}

waveguide would need to deliver approximately $3 \mathrm{~kW}$ of acoustic power in order to make up for losses incurred along the system.

A prototype delivery system was assembled and tested. A 4-in. diameter, $20-\mathrm{kHz}$ transducer was driven by a signal generator and power amplifier with 2 msec pulses at a $10-\mathrm{Hz}$ repetition rate. This mode of operation avoids the problem of cavitation in the waveguide fluid. The peak acoustic output at the transducer face was $1 \mathrm{w} / \mathrm{cm}^{2}$. The transducer was coupled to a 1 -meter long, $1-1 / 2$ in. Schedule 40 stainless steel tube filled with GE FS1154 silicone oil via a conical fluid-filled horn. A radiator consisting of a 1 -foot long section of the same tubing containing four conical reflectors was attached to the lower end of the waveguide and submersed in a water tank. The complete system is shown in Figure 1 in schematic form.

A B\&K hydrophone was used to probe the cylindrical acoustic output field. At a distance of 44 inches from the radiator, a peak output of $215 \mu \mathrm{W} / \mathrm{cm}^{2}$ was measured. The transducer area of $81.1 \mathrm{~cm}^{2}$ projects a total of 81.1 peak watts of power into the waveguide. At the hydrophone position of $44 \mathrm{in}$., the cylindrical surface area insonified by the radiator is about $4.22 \times 10^{4} \mathrm{~cm}^{2}$, for a total power of 9.07 watts peak. The efficiency of power transfer was, therefore, $11.2 \%$. This is very good considering the thick walls of the 
radiator. A Schedule 5 radiator tube should increase the transfer efficiency to about $50 \%$.

Experimental data shown in Figure 2 verifies the concept of the radiator as a plane-to-cylindrical wave converter. Note that near the radiator, the field is very nonuniform, while at a further distance it is smooth, as predicted. 


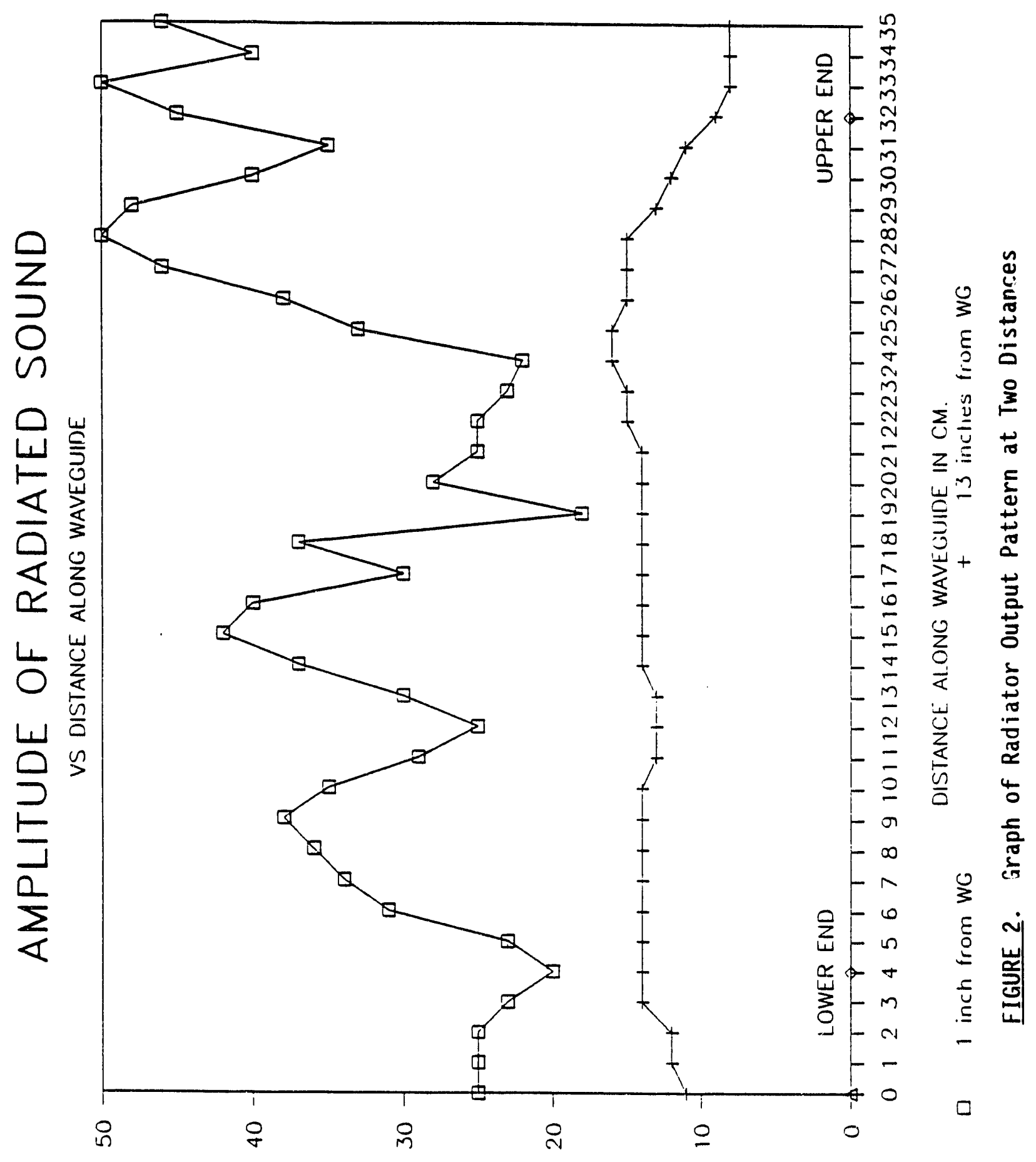

$\exists \wedge \forall M$ JILกOJ 


\section{ULTRASONIC PROPERTY MEASUREMENT}

The basic experimental arrangement is shown in Figure 3. A high-power transducer $4 \mathrm{in}$. in diameter, and designed to operate in the range of 5 to 50 $\mathrm{kHz}$, was used as the acoustic source. This transducer was driven with an RF amplifier with a peak output of 200 watts. A variable frequency signal generator supplied the input to the RF amplifier. A plexiglass cylinder open on both ends was affixed directly onto the transducer iace with RTV. The waste simulant, prepared at the Pacific Northwest Laboratory (PNL) to be chemically similar to the slurry contained in Tank 101-SY, was then poured into the cylindrical volume in direct contact with the transducer face. ${ }^{1}$ The depth of the slurry was about $5 \mathrm{~cm}$. A Bruel and $\mathrm{Kjaer}$ hydrophone was then lowered into the simulant. Its vertical position within the simulant was controlled with a micrometer screw adjustment, and its relative position could be read from a dial to a precision of $0.1 \mathrm{~mm}$. The hydrophone was connected to an oscilloscope or, in subsequent experiments, a high-frequency voltmeter to monitor the amplitude of the acoustic signal. All experiments used the arrangement shown in Figure 3 and the same measurements were made in these experiments. Changes were made in the condition of the slurry sample in different experiments. For example, the slurry sample was de-gassed in one set of experiments, heated in another set, pressurized in a third, and diluted in a fourth. These experiments will be discussed below.

\section{ATTENUATION MEASUREMENTS}

A typical experiment was conducted in the following manner. The hydrophone was first located somewhere near the bottom of the simulant, but not directly on the bottom. The location of the hydrophone as read from the micrometer was recorded. The RF amplifier was then adjusted to give a fullscale reading of the hydrophone signal on the oscilloscope. The output of the amplifier was a continuous sinusoidal signal, and the peak intensity measured with the hydrophone was $50 \mathrm{~mW} / \mathrm{cm}^{2}$. Then the hydrophone was moved upward away

\footnotetext{
${ }^{1}$ The chemical constituents and conditioning procedure are presented in Appendix 1 .
} 


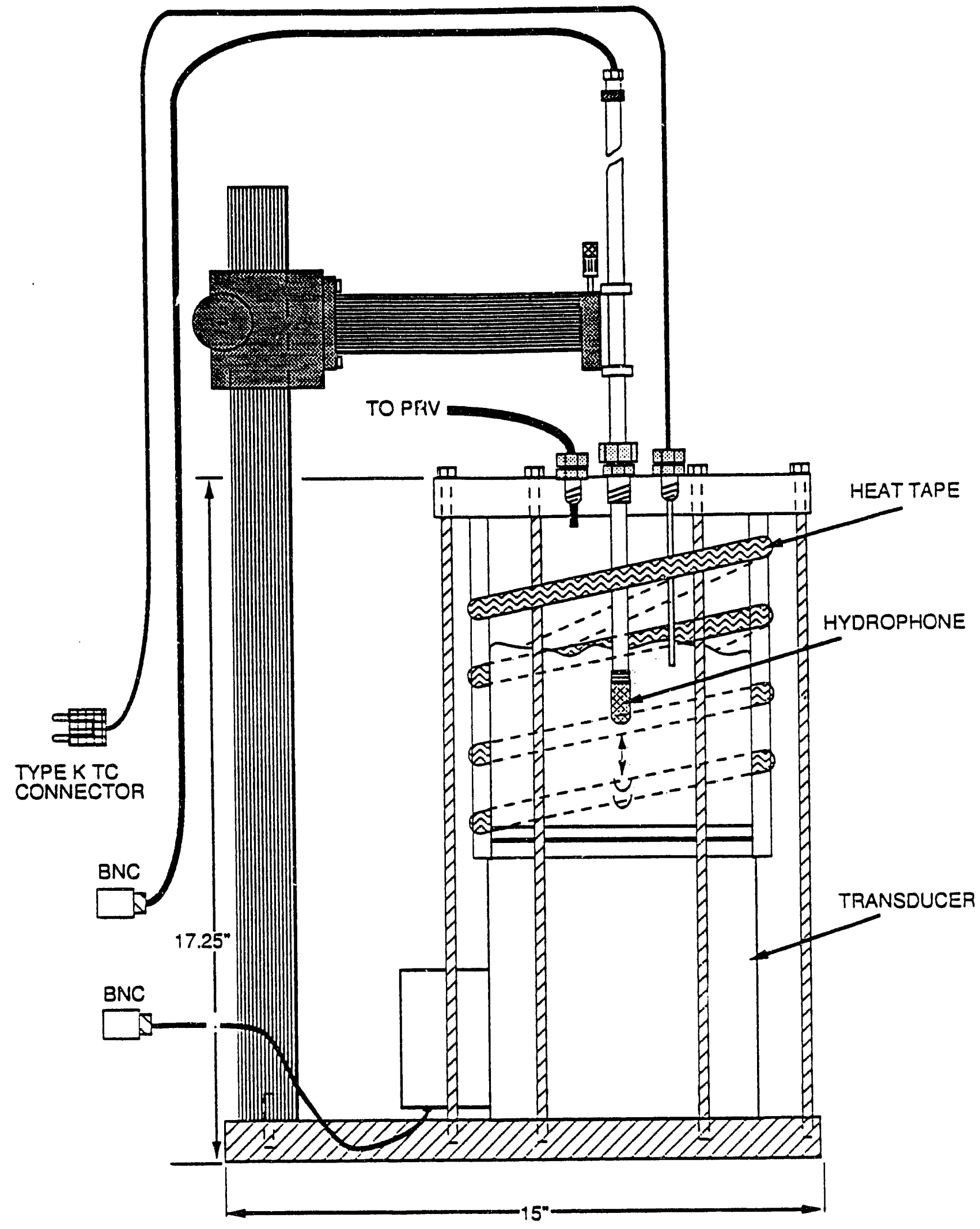

FIGURE 3. Experimental System for U1trasonic Property Measurement 
from the bottom of the slurry until the oscilloscope signal amplitude was reduced to a chosen target value (about $1 / \mathrm{e}$ of the original signal). The position of the hydrophone was again recorded. The hydrophone was further withdrawn from the waste until a second target amplitude was observed on the oscilloscope (again, about $1 / \mathrm{e}$ of the previous signal, or $1 / \mathrm{e}^{2}$ of the original signal) and the position of the hydrophone was recorded. After this, the hydrophone was returned to its original position to check that the amplitude was once again the original full-scale amplitude. In most cases, this condition was fulfilled. In this manner, we were able to obtain signal amplitude as a function of position for two locations in addition to the reference location. In initial experiments using the original simulant, identical measurements were performed at transducer frequencies of 10, 20, and $30 \mathrm{kHz}$. The results of the experiments are shown in Figure 4, where the logarithm of the signal amplitude is plotted against position. The slopes of these curves provide the attenuation coefficients.

The hydrophone signal, $S$, obeys the relationship

$$
S=S_{o} e^{-\alpha x}
$$

where $S_{0}$ is some initial amplitude at $x=0, x$ is the distance from some reference location, and $\alpha$ is the attenuation coefficient. Taking the natural logarithm of Eq. (6) yields

$$
\ln \frac{S}{S_{o}}=-\alpha x
$$

Thus a plot of $\ln \left(S / S_{0}\right)$ versus distance should yield a straight line whose slope is $-\alpha$, as observed in the curves of Figure 4. Analysis of these curves gives the attenuations shown in Table 4 . The measured attenuations are quite high. The uncertainty in the measured values is about $10 \%$. Because of their magnitude, no effects due to standing wave phenomena within the simulant are expected or observed. 
ACOUSTIC ATTENUATION IN DST WASTE SIMULANT

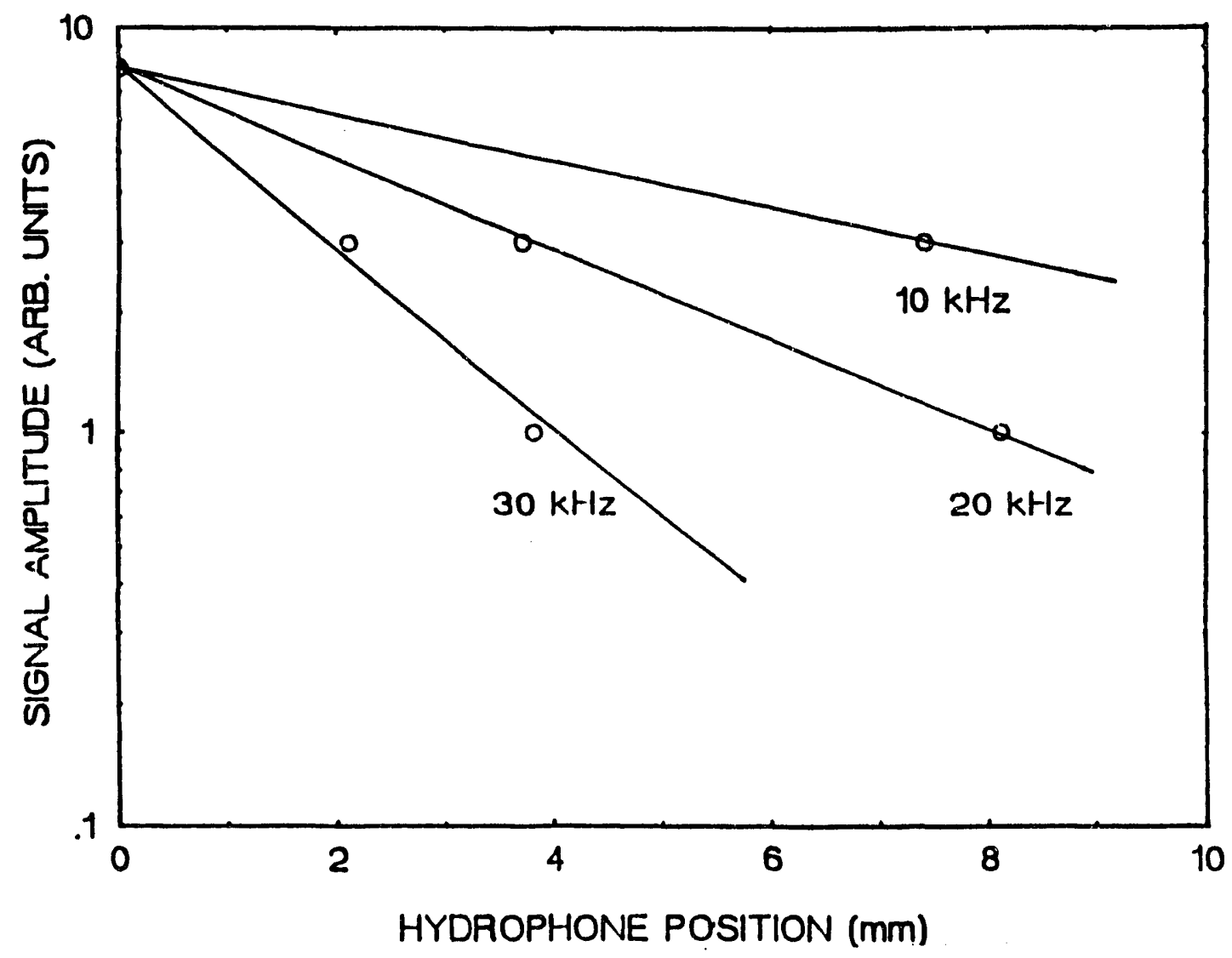

FIGURE 4. Attenuation Measurements for a Chemical Simulant Slurry at Room Temperature and Ambient Pressure

\section{DEGASSING EXPERIMENTS}

The simulant underwent no preparation in initial experiments described above. There is some belief that gas bubbles contained in the simulant may be responsible for the exceedingly high attenuation. Subsequent experiments which we will now discuss have shown, however, that the attenuation cannot be attributed solely to gas bubbles. In fact, it is observed that attenuation generally increases as the volume of gas contained in the simulant decreases, at least for the bubble concentrations studied here.

Initial slurry preparation served both to de-gas the simulant and establish the gas content and bubble size within the slurry. First the 
TABLE 4. Acoustic Attenuation of Chemical Simulant at Various Frequencies and Void Fractions

\begin{tabular}{|c|c|c|c|}
\hline $\begin{array}{c}\text { Simulant Condi- } \\
\text { tion }\end{array}$ & Frequency, $\mathrm{kHz}$ & Attenuation, $\mathrm{Np} / \mathrm{cm}$ & $\begin{array}{c}\text { Attenuation, } \\
\mathrm{dB} / \mathrm{m}\end{array}$ \\
\hline \multirow[t]{3}{*}{ As Is } & 10 & 1.3 & 1100 \\
\hline & 20 & 2.6 & 2200 \\
\hline & 30 & 5.5 & 4800 \\
\hline \multirow{3}{*}{$\begin{array}{c}\text { Void Fraction } \\
0.13 \%\end{array}$} & 10 & 3.2 & 2780 \\
\hline & 20 & 4.9 & 4300 \\
\hline & $3 C$ & 4.9 & 4300 \\
\hline \multirow[t]{3}{*}{$\begin{array}{c}\text { Void Fraction } \\
0.07 \% \\
\end{array}$} & 10 & 4.6 & 4000 \\
\hline & 20 & 6.2 & 5400 \\
\hline & 30 & $\ldots$ & $\ldots$ \\
\hline
\end{tabular}

simulant was poured from its container into the plexiglass cylinder affixed to the high-power transducer. A steel ruler was attached to the cylinder so fluid height measurements could be obtained. The transducer and waste were placed in a bell jar whose atmosphere could be evacuated with a standard mechanical pump to a pressure of about $1 \mathrm{~mm} \mathrm{Hg}$. Upon evacuation of the bell jar, the slurry height was observed to increase by $1.0 \mathrm{~cm}$ initially. After repeated evacuations which occurred throughout the day, the fluid height increased by $0.5 \mathrm{~cm}$ upon pumpdown. The increase in height of the fluid was due to expansion of the gas held within the fluid as the pressure was reduced. The pressure was initially 1 atm plus hydrostatic pressure and pumping reduced this to just the hydrostatic fluid pressure, about $4 \mathrm{~mm} \mathrm{Hg}$ at the center of the fluid. It can be concluded from the expansion data that about half of the gas volume was eventually removed by vacuum pumping. Some bubbles were observed to come to the surface of the fluid, but many apparently did not leave the fluid. Bubbles could be seen near the plexiglass-fluid boundary, and these were estimated to be of a diameter of 0.5 to $1.0 \mathrm{~mm}$. These bubbles became small and disappeared when atmospheric pressure was allowed back into the bell jar. 
The void fraction and bubble size in the de-gassed slurry can be estimated with reference to Figure 5. The trapped gas follows the ideal gas law relation

$$
P_{1} V_{1}=P_{2} V_{2}
$$

where $P_{1}=760 \mathrm{~mm} \mathrm{Hg}(1 \mathrm{~atm})+4 \mathrm{~mm} \mathrm{Hg}$ (hydrostatic pressure at fluid center) and $P_{2}=4 \mathrm{~mm} \mathrm{Hg}$. The volume $V_{2}$ is given by the product of the cylinder area and height of the slurry growth. From the data above, this gives

$$
V_{2}=A(1.0) \mathrm{cm}^{3}
$$

where $A$ is the cross-sectional area of the plexiglass cylinder. Theri the volume occupied by the gas when atmospheric pressure is present is calculated to be

$$
V_{1}=\frac{4}{764} A(1.0) \mathrm{cm}^{3}
$$

The height of the fluid in the presence of atmospheric pressure was measured beforehand to be $3.91 \mathrm{~cm}$, and thus the total fluid volume is given by

$$
V_{t}=3.91 \mathrm{~A} \mathrm{~cm}^{3}
$$

The void fraction is simply the ratio $V_{1} / V_{t}$, and is calculated to be

$$
\frac{V_{1}}{V_{t}}=1.3 \times 10^{-3}
$$

The actual volume of gas contained within the simulant is seen to be quite small, both before and after de-gassing. De-gassing appeared to reduce gas volume by about a factor of two. The void fraction given above represents the initial gas content of the simulant. The void fraction near the end of testing was about half of this value. 


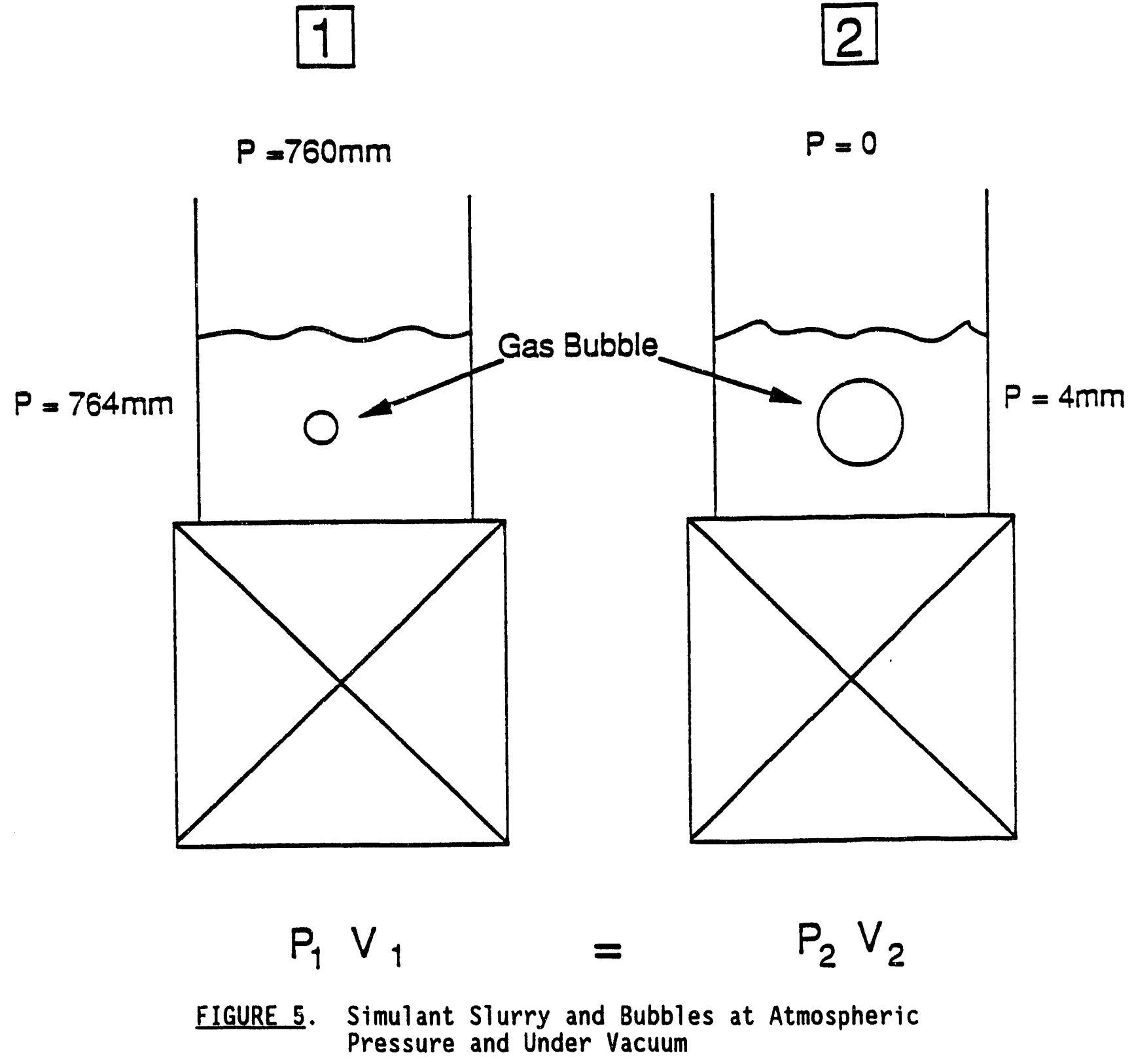

Bubble size can also be estimated from these calculations and from observations of bubble size under vacuum conditions. The ratio of gas volumes (which is also the ratio of the diameters to the third power) with and without atmospheric pressure is, from Eq. (8) 


$$
\frac{V_{1}}{V_{2}}=\left(\frac{D_{1}}{D_{2}}\right)^{3}=\frac{4}{764}
$$

Thus the ratio of the diameters is given by

$$
\frac{D_{1}}{D_{2}}=0.17
$$

It is observed that $D_{2}=0.5$ to $1.0 \mathrm{~mm}$, so

$$
0.09 \mathrm{~mm} \leq D_{1} \leq 0.17 \mathrm{~mm}
$$

It is further observed that the bubbles clearly visible under vacuum conditions disappear when atmospheric pressure is applied. A typical size limit for viewing objects with the unaided eye is about $0.1 \mathrm{~mm}$. From these calculations and observations, it is quite likely that most bubbles are of a diameter less than or about $0.1 \mathrm{~mm}$ when atmospheric pressure is present.

After de-gassing, attenuation measurements were performed as described above. The results of these measurements are shown collectively in the plots of Figure 6. The attenuation coefficients at 10, 20, and $30 \mathrm{kHz}$ are shown in Table 4 for all simulant conditions, i.e., "as is" and with void fractions of $0.13 \%$ and $0.07 \%$.

It is seen from this table that the observable effect of de-gassing has been to increase the attenuation at frequencies of 10 and $20 \mathrm{kHz}$. At $30 \mathrm{kHz}$ the available data show no significant change in attenuation with de-gassing. The data would seem to suggest that gas bubbles are not the cause of the high attenuation coefficient for this simulant. However, we have measurements only over a limited range of void fraction, and more data, especially at lower void fraction, are needed before firm conclusions can be drawn. As demonstrated earlier, we believe that the bubbles are predominantly less than or about 0.1 $\mathrm{mm}$ in diameter. Previous work has shown that the resonant absorption frequency for a $0.1-\mathrm{mm}$ diameter bubble in water is about $65 \mathrm{kHz}$. A plot of the resonant frequency as a function of bubble diameter is shown in Figure 7 for bubbles in water. For other fluids, the resonant frequency scales inversely as the square root of the fluid density. For the simulant which has 
ANOUS TIC A T TENUA TION IN A DE-GASSED SLURRY

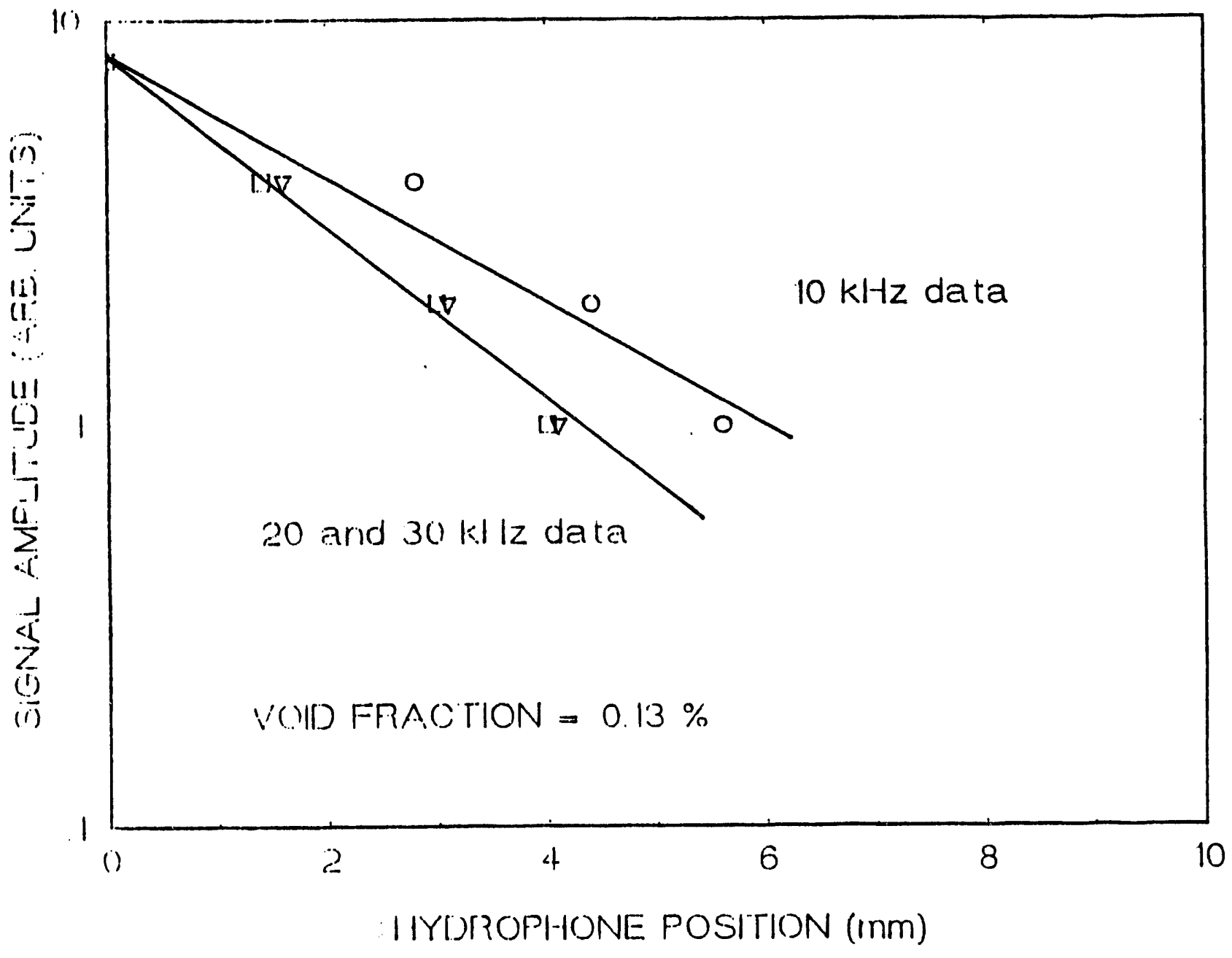

FIGURE 6. Acoustic Attenuation in a De-Gassed Slurry

a density of about $2 \mathrm{~g} / \mathrm{cm}^{3}$, the expected resonant frequency would be about 45 $\mathrm{KHz}$ for a bubble of diameter $0.1 \mathrm{~mm}$. It appears that the bubbles in this slurry are too small to absorb acoustic energy at frequencies of $30 \mathrm{kHz}$ or less. Then the observed fact that attenuation does not decrease as gas is removed from the simulant becomes understandable since the bubbles should not affect absorption. It remains to be explained why attenuation increases for 10- and 20-kHz ultrasound as the void fraction is decreased. Also, why isn't the 30-kHz data similarly affected? At present we do not have good answers to 


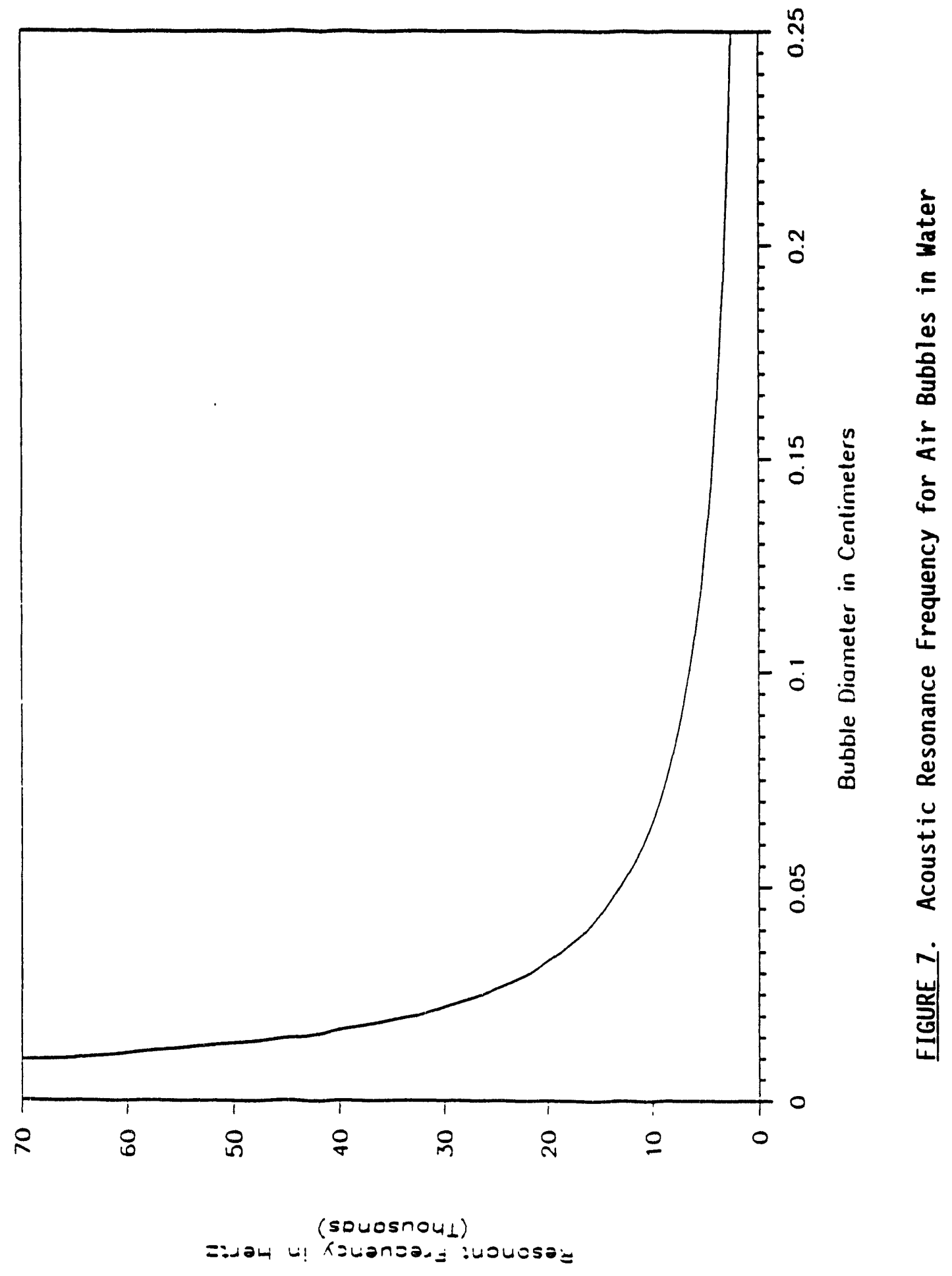


these questions. In some fashion, the slurry has been changed by our attempts to degas it or by our vigorous ultrasonic agitation. The removal of gas and the replacement of it with the simulant does not seem like a reasonable cause for the attenuation increase, which is about a factor of two at 10 and $20 \mathrm{kHz}$. Volumetrically, very little gas was removed. Another process which occurs during the de-gassing procedure is evaporation of the fluid. The fluid level was observed to decrease by $0.1 \mathrm{~cm}$ (initial fluid depth was $3.9 \mathrm{~cm}$ ) during the course of the day, about 30 iimes more than expected from just de-gassing. Perhaps the drying of the fluid has led to a significantly more viscous fluid with greater attenuation. The main conclusions which can be drawn are that the simulant is quite attenuative to ultrasound and this attenuation is not solely due to the bubbles entrained within the fluid. Further experimentation is needed in order to fully understand the phenomena described here.

\section{EXPERIMENTS IN HEATED SLURRY}

Additional experiments were performed for measurement of chemical waste simulant attenuation ar temperatures ranging from 24 to $76^{\circ} \mathrm{C}$. The two experiments described above demonstrate very high acoustic attenuation of natural and de-gassed simulant in excess of $1000 \mathrm{~dB} / \mathrm{m}$ at 10,20 , and $30 \mathrm{kHz}$. Because of results obtained by Steve Aynew at LANL and Rudy Alleman at PiN!., wherein significant changes in the structure of the simulant occurred at around $65^{\circ} \mathrm{C}$, we decided to find out if concomitant attenuation changes also occurred.

The experimental set-up is again shown in figure 3 . The transducer and plexiglass cylinder were of such a height as to fit into a temperaturecontrolled oven. The plexiglass cylinder was filled to a depth of $8 \mathrm{~cm}$ with simulant; and ihe transducer, cylinder, and simulant were placed in the oven, which was se at $60^{\circ} \mathrm{C}$. After four hours, the arrangement was removed and set into the measuring apparatus. Attenuation measurements were made at a variety of temperatures as the simulant cooled back down to room temperature. Unfortunately, the highest temperature reached by the simulant was only $53^{\circ} \mathrm{C}$, so our original goal was rot achieved. The results of this test verified the high attenuation numbers measured at roomi temperature and reported in Table 4. 
Because we wished to make measurements at higher temperatures, and did not wish to wait so long for the oven to attain them, we decided to attempt ultrasonic heating of the waste. Consequently, we drove the transducer at maximum power (200 watts) and were surprised to find that a high rate of heating occurred $\left(30^{\circ} \mathrm{C}\right.$ per hour). We subsequently made attenuation measurements at $60,67,72$, and $76^{\circ} \mathrm{C}$. The result at $60^{\circ} \mathrm{C}$ was similar to our previous figures, but at $67^{\circ} \mathrm{C}$, attenuation had become low enough to cause problems with standing waves.

Physical observations during the heating process explained the acoustic phenomenon, in that the crystallites in the simulant dissolved, leaving a fluid free of particulates. At the same time, bubbles which had presumably been attached to the crystallites were released from the free surface of the simulant. The layer of crystallite-free fluid grew up from the transducer as the heating continued, until at the end of the experiment it constituted about half the volume. The upper region appeared frothy.

After reaching $80^{\circ} \mathrm{C}$ our transducer lost most of its output, and the simulant cooled back down to room temperature. The lower layer recrystallized and the top became crusty. However, the texture and color of the two layers remained distinct.

In addition, a thin hard layer $(1 \mathrm{~cm})$ formed at the very bottom. This seemed to be made up of packed crystals and had to be broken with a spatula in order to remove it after the liquid contents were poured off.

Our conclusion is that the abundance of crystallites within the slurry contributes to the high attenuation. At a critical temperature (approximately $65^{\circ} \mathrm{C}$ ) the crystallites dissolve, releasing trapped bubbles which then float to the surface. The dissolution of the crystallites results in greatly reduced acoustic attenuation. In this experiment we could not determine the attenuation coefficient, because standing waves between the transducer and the boundary preclude the use of our measurement method. However, we have performed somewhat more refined experiments from which we estimate that the attenuation coefficient is about $500 \mathrm{~dB} / \mathrm{m}$ at $10 \mathrm{kHz}$. 


\section{EXPERIMENTS IN PRESSURIZED SLURRY}

The depth of the sludge layer in the DSTs is 30 to 40 feet, which means that this layer is under approximately 1 atm of excess pressure.

Consequently, bubbles present in the sludge will be compressed, and the crystallites will be more closely packed. Intuitively, this means that acoustic attenuation should decrease. We have verified this premise by measuring the attenuation during pressurization of the waste container with compressed air. The results of this experiment are shown in Table 5 . In addition to reduced attenuation, more energy is transferred to the waste due to better coupling. This can be measured by keeping the hydrophone at a fixed position and reading its output as a function of pressure. Such a curve is shown in Figure 8 . Using these results we conclude that $20 \mathrm{~dB}$ may be gained simply due to the increased coupling.

Other measurements made during this experiment were velocity of propagation and cavitation threshold. The former was obtained by observing the phase change as the hydrophone was moved between two positions away from the transducer. The latter was estimated by observing the waveform as the power was increased until it changed from a steady sinusoidal shape to a jumpy, noisy signal, which is necessarily a very subjective measure. The results are shown in Table 6 .

From these data, we see that increasing pressure has a beneficial effect due to a decrease in attenuation and an increase in coupling efficiency. In addition, the velocity of propagation and cavitation threshold increases.

TABLE 5. Attenuation as a Function of Pressure

\begin{tabular}{|c|c|c|}
\hline Frequency, $\mathrm{kHz}$ & $\begin{array}{c}\text { Attenuation, } \mathrm{dB} / \mathrm{m}, \text { at } 1 \\
\mathrm{~atm}\end{array}$ & $\begin{array}{c}\text { Attenuation, } \mathrm{dB} / \mathrm{m} \text { at } 2 \\
\mathrm{~atm}\end{array}$ \\
\hline 10 & 1415 & 791 \\
\hline 20 & 4704 & 1747 \\
\hline 30 & \multicolumn{2}{|c|}{ Too high to measure reliably } \\
\hline
\end{tabular}




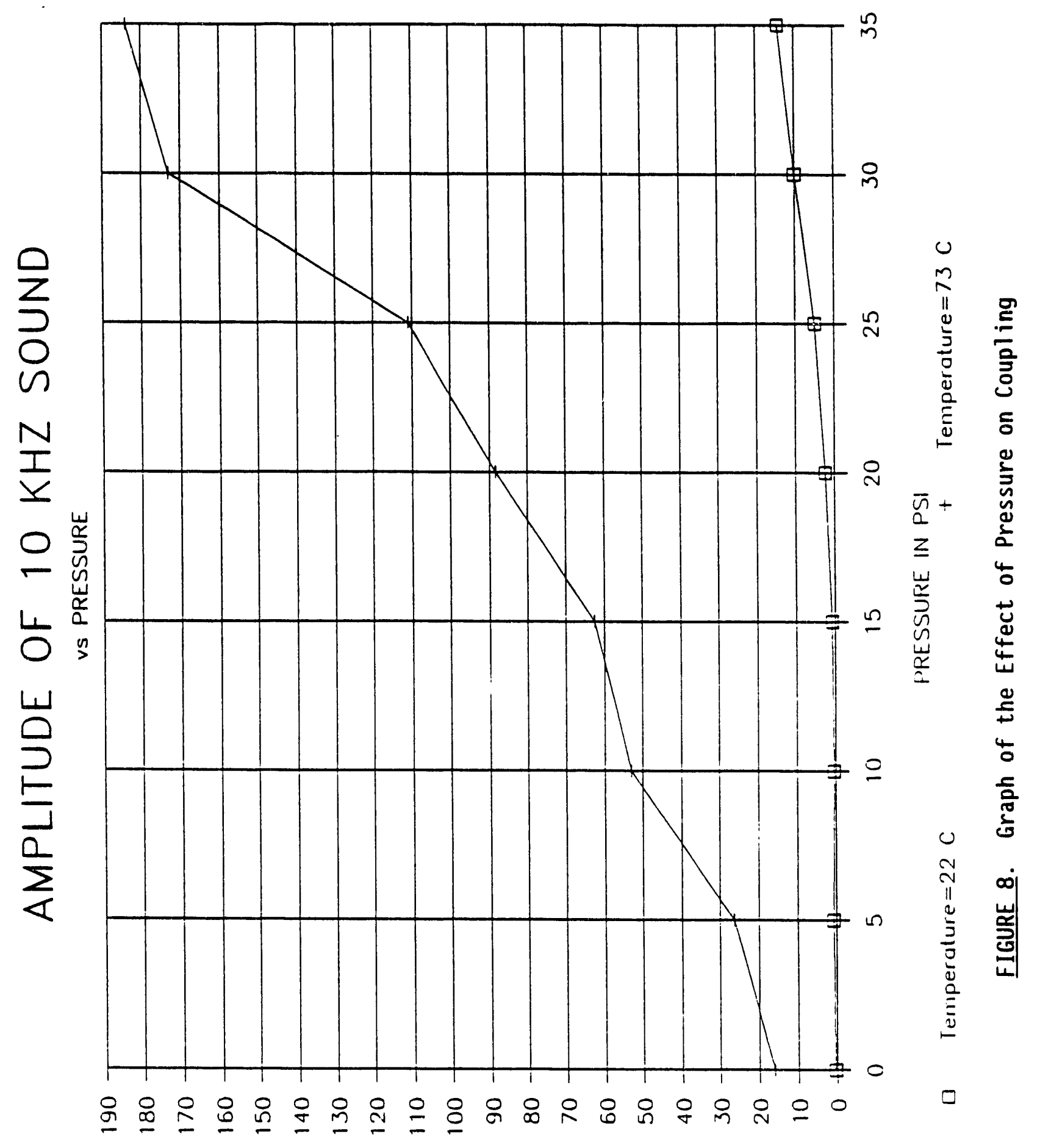

sسد^س NI $\exists O \cap 117 d W \forall$ 
TABLE 6. Velocity and Cavitation Threshold as a

Function of Temperature and Pressure

\begin{tabular}{|c|c|c|c|c|}
\hline \multirow{2}{*}{$\begin{array}{c}\text { Pressure, } \\
\text { atm }\end{array}$} & \multicolumn{2}{|c|}{ Velocity, cm/sec $\times 10^{4}$} & \multicolumn{2}{c|}{ Cavitation Threshold, w/cm2 } \\
\cline { 2 - 5 } & $22{ }^{\circ} \mathrm{C}$ & $70^{\circ} \mathrm{C}$ & $22{ }^{\circ} \mathrm{C}$ & $70^{\circ} \mathrm{C}$ \\
\hline 1 & 2.15 & 3.2 & 0.0012 & 0.0005 \\
\hline 2 & 3.05 & 6.3 & 0.012 & 0.05 \\
\hline
\end{tabular}

\section{EXPERIMENTS IN DILUTED SLURRY}

The last experiment sought to investigate the effect of dilution on the acoustic parameters. The diluent consisted of a $0.01 \mathrm{M} \mathrm{NaOH}$ solution which was mixed with the slurry to achieve $10 \%$ and $20 \%$ dilution. These mixtures were then subjected to the same tests as described previously. Table 7 provides the results of this experiment.

\section{MITIGATION POWER EXPERIMENT}

A crucial measurement is required in addition to attenuation; the intensity required to set the bubbles into motion. This is an exceedingly difficult measurement to make in the optically opaque slurry. Consequently, we used a 100 centipoise silicone $0 i l$ viscosity standard as a surrogate. Air

TABLE 7. Attenuation as a Function of Dilution and Pressure

\begin{tabular}{||c|c|c|c|c||}
\hline \multirow{2}{*}{$\begin{array}{c}\text { Frequency, } \\
\mathrm{kHz}\end{array}$} & $\begin{array}{c}\text { Pressure, } \\
\text { atm }\end{array}$ & \multicolumn{3}{|c|}{ Attenuation, dB/m, with Dilution of } \\
\cline { 3 - 5 } & 1 & $0 \%$ & $10 \%$ & $20 \%$ \\
\hline \multirow{3}{*}{10} & 2 & 1415 & 1131 & 847 \\
\cline { 2 - 5 } & 1 & 791 & 520 & 437 \\
\hline \multirow{3}{*}{30} & 2 & 4704 & 3473 & 1592 \\
\cline { 2 - 5 } & 1 & 1747 & 1039 & 881 \\
\hline \multirow{2}{*}{30} & 2 & Too high to measure & 3367 \\
\cline { 2 - 5 } & & Too high to measure & 1854 \\
\hline
\end{tabular}


bubbles were injected into the optically clear liquid and $20-\mathrm{kHz}$ sound pulsed at a $2-\mathrm{Hz}$ rate with $50 \mathrm{msec}$ pulse length introduced. The intensity was increased until the bubbles began to jiggle at the $2-\mathrm{Hz}$ rate. This intensity was measured at $12 \mathrm{mw} / \mathrm{cm}^{2}$. Although a pure liquid, such as silicone $0 i 1$, is quite different than the simulant, the viscosity was comparable.

Consequently, we feel comfortable with this measurement value, particularly because Steve Agnew of LANL arrived at a similar value. 


\section{CONCLUSIONS}

The power transfer concept utilizing a liquid-filled waveguide and planeto-cylindrical wave radiator worked as predicted. By utilizing short pulses, cavitation in the fluid was avoided. The percent power transfer of $11.2 \%$ from the transducer to the waste was just as predicted by the theory. A thinning of the radiator wall thickness could easily increase power transfer to $50 \%$ or higher.

Attenuation of the simulated slurry is too high, under all tested conditions, to make ultrasonic mitigation a practical technique. The lowest attenuation measured was $437 \mathrm{~dB} / \mathrm{m}$ for $20 \%$ dilution and $2 \mathrm{~atm}$ of pressure. Heating the simulant to $65^{\circ} \mathrm{C}$ halves the attenuation, so that a combination of heating and dilution along with the pressure of $2 \mathrm{~atm}$ at the bottom of the tank should reduce attenuation to approximately $200 \mathrm{~dB} / \mathrm{m}$ at $10 \mathrm{kHz}$. This means that if the waste can withstand the measured cavitation threshold power of $50 \mathrm{mw} / \mathrm{cm}^{2}$ (see Table 3) and the mitigation power is as measured at 12 $\mathrm{mw} / \mathrm{cm}^{2}$, the required effective action range becomes $3.1 \mathrm{~cm}$. This is obviously too low to have any practical value.

A full understanding of the physical and chemical parameters which affect attenuation is not presently at hand. Further experimentation with modified test procedures are needed in order to separate the effects of test variables. For instance, ultrasound could be applied in a manner which does not produce significant heating of the slurry, while heating is performed separately by more traditional means. It is also important to understand that a chemical simulant is not necessarily a correct rheological simulant, and ultimately experiments should be performed using an actual sample of Tank 101-SY waste. Discussions with the staff operating the hot ceil facilities should be held and experiments should be designed for use in the hot cell after sufficient cold testing with simulants. The goals of the additional experiments would be to gain a deeper appreciation of the role of rheology, crystalline structure, and gas bubble content in determination of the attenuation coefficient, and a final determination of the feasibility of ultrasonic bubble mitigation. Presently, the outlook for such a mitigation strategy looks poor considering 
the data gathered thus far. However, definite conclusions cannot be made at this time. 


\section{REFERENCES}

Ensminger, Dale. 1973. Ultrasonics, The Low- and High-Intensity Applications, Marcel Dekker, Inc., New York, New York.

Pierce, Allan D. 1981. Acoustics, An Introduction to Its Physical Principles and Applications, McGraw-Hill, Inc., New York, New York. 


\section{BIBLIOGRAPHY}

Edmonds, Peter D., Ed. 1981. Ultrasonics, Vol. 19 of Methods of Experimental Physics, Academic Press, New York, New York.

Herzfeld, Karl F. and Theodore A. Litovitz. 1959. Absorption and Dispersion of Uitrasonic Waves, Academic Press, New York, New York.

Rozenberg, L. D. 1971. High-Intensity Ultrasonic Fields, Plenum Press, New York, New York.

Towne, Dudley H. 1967. Wave Phenomena, Addison-Wesley Publishing Co., Reading, Massachusetts.

Urick, Robert J. 1967. Principles of Underwater Sound, McGraw-Hill Book Co., New York, New York. 
APPENDIX A

FORMULATION AND CONDITIONING OF THE WASTE SIMULANT 
APPENDIX A

\section{FORMULATION AND CONDITIONING OF THE WASTE SIMULANT}

The simulant is designed to be similar to the waste contained in 101-SY including chemical and physical makeup. This requires the accurate reproduction of the chemical content, and conditioning to attain similar physical properties and distribution as occurs naturally in the tank.

Two batches of simulant were used in this investigation. The chemical constituents, shown in Tables A.1 and A.2, are very similar, and represent the makeup of core samples taken at different times. The difference in acoustic properties and visual appearance were, however, quite striking. The first batch had a smooth texture and a beige color. The second batch was more granular and had a darker rust color. As for attenuation, the first was 1100 $\mathrm{dB} / \mathrm{m}$ and the second was $2400 \mathrm{~dB} / \mathrm{m}$ at $10 \mathrm{kHz}$ and room temperature.

The conclusion must be that the simulant can only provide an indication of the true acoustic properties. Hot cell tests on actual core samples must be performed to provide better data.

The conditioning of the simulant causes it to settle out into sludge, supernatant, and crust with each constituent similar to these layers as seen in core samples. This process, developed by Alleman ${ }^{2}$, consists of the following steps.

1) Heat to $80^{\circ} \mathrm{C}$ and hold for 24 hours

2) Let cool to room temperature

3) Mix the cooled material

4) Heat to $60^{\circ} \mathrm{C}$ and hold for 24 hours

5) Let cool to room temperature

After this process, the mixture will settle out into the three layers described above. The sludge will contain crystals similar in type and habit

${ }^{2}$ Alleman, R. J. 1991. Physical Modelling to Support Flammable Gas Waste Tank Mitigation - Chemical simulant Testing, PNL Progress Report. 
sludge, thus providing a good test of the acoustic mitigation method.

The experiments described in the body of this report were performed on the sludge, obtained by removing the crust and carefully poring off the supernate.

IABLE A.1. Composition of Synthetic Waste used for Chemical Simulant Testing - Batch 1

\begin{tabular}{||l|c|c|c||}
\hline \multicolumn{1}{|c|}{ Component } & F. Wt., g/mol & M, mole/L & Grams \\
\hline NaA102 & 82 & 2.1 & 2066.40 \\
\hline Na4EDTA & 380.18 & 0.17 & 775.57 \\
\hline $\mathrm{Na3HEDTA}$ & 380.24 & 0.35 & 1597.01 \\
\hline $\mathrm{NaCl}$ & 58.44 & 0.35 & 245.45 \\
\hline $\mathrm{Na3P04}$ & 380.13 & 0.2 & 912.31 \\
\hline $\mathrm{NaNO2}$ & 69 & 3.1 & 2566.80 \\
\hline $\mathrm{NaNO3}$ & 84.99 & 3.1 & 3161.63 \\
\hline $\mathrm{Na2C03}$ & 105.99 & 0.4 & 508.75 \\
\hline $\mathrm{NaF}$ & 41.99 & 0.1 & 50.39 \\
\hline $\mathrm{NaOH}$ & 40 & 2.9 & 1392.00 \\
\hline $\mathrm{Cr}(\mathrm{NO3}) 3$ & 400.15 & 0.0015 & 7.2027 \\
\hline $\mathrm{Cu}(\mathrm{NO3}) 2$ & 232.59 & 0.00021 & 0.5861268 \\
\hline $\mathrm{Fe}(\mathrm{NO3}) 3$ & 404 & 0.002 & 9.696 \\
\hline $\mathrm{Ni}(\mathrm{NO3}) 2$ & 290.81 & 0.0031 & 10.818132 \\
\hline $\mathrm{H}, \mathrm{O}$ & 18 & & 5800 \\
\hline
\end{tabular}


TABLE A.2. Composition of Synthetic Waste used for Chemical Simulant Testing - batch 2

\begin{tabular}{|l|c|c|c||}
\hline \multicolumn{1}{|c|}{ Component } & F.Wt., g/mol & M, mole/L & Grams \\
\hline NaA102 & 115 & 2.05 & 2829.00 \\
\hline Na4EDTA & 380.18 & 0.066 & 301.10 \\
\hline Na3HEDTA & 380.24 & 0.135 & 615.991 \\
\hline $\mathrm{NaCl}$ & 58.44 & 0.526 & 368.87 \\
\hline $\mathrm{Na3P04}$ & 380.13 & 0.179 & 816.52 \\
\hline $\mathrm{NaN02}$ & 69 & 3.95 & 3270.60 \\
\hline $\mathrm{NaN03}$ & 84.99 & 2.2 & 2243.74 \\
\hline $\mathrm{Na2C03}$ & 105.99 & 0.4 & 508.75 \\
\hline $\mathrm{NaF}$ & 41.99 & 0.1 & 50.39 \\
\hline $\mathrm{NaOH}$ & 40 & 2.45 & 1176.00 \\
\hline $\mathrm{Cr}(\mathrm{NO3}) 3$ & 400.15 & 0 & 00.00 \\
\hline $\mathrm{Cu}(\mathrm{NO3}) 2$ & 232.59 & 0.00021 & 0.59 \\
\hline $\mathrm{Fe}(\mathrm{NO3}) 3$ & 404 & 0.0074 & 35.88 \\
\hline $\mathrm{Ni}(\mathrm{NO3}) 2$ & 290.81 & 0.0021 & 7.33 \\
\hline $\mathrm{Na} 2 \mathrm{SO4}$ & 142.04 & 0.032 & 54.54 \\
\hline $\mathrm{CaCl2}$ & 110.99 & 0.0083 & 11.05 \\
\hline $\mathrm{KCl}$ & 74.56 & 0.146 & 130.63 \\
\hline $\mathrm{H}$ 20 & 18 & & 5800 \\
\hline
\end{tabular}




\section{DISTRIBUTION}

No. of

Copies

\section{OFFSITE}

2 DOE/Office of Scientific and Technical Information

\section{ONSITE}

DOE Richland Field Office

R. F. Christenson

7 Westinghouse Hanford Company

H. Babad

T. M. Burke

M. N. Hall

G. D. Johnson

N. W. Kirch

J. W. Lentsch

D. A. Reynolds

14 Pacific Northwest Laboratory

R. T. Allemann

J. B. Colson

B. P. Hildebrand

M. R. Kreiter

C. L. Shepard (3)

D. M. Strachan Publishing Coordination

Technical Report Files (5) 

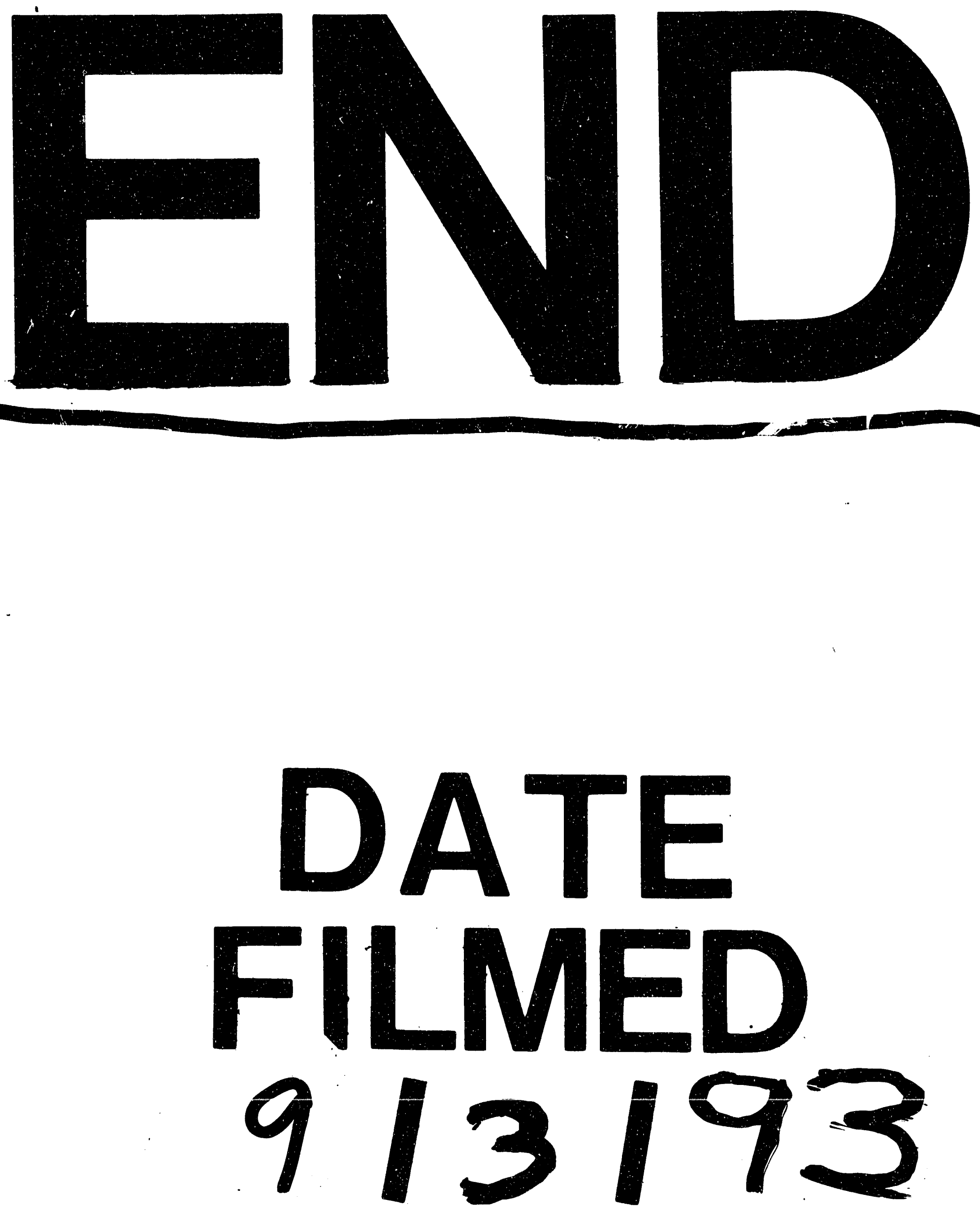
1 